\title{
Brief Analysis of Schools Enterprises Cooperation Teaching in Colleges and Universities in the Era of Big Data
}

\author{
Liming Cui \\ College of Art and Design, Changchun University of Technology, Changchun City, Jilin Province, \\ China, 130012 \\ Cuiliming@ccut.edu.cn
}

Keywords: Big data; Schools enterprises cooperation; Teaching

\begin{abstract}
This paper analyzes the current situation of the traditional schools enterprises cooperation teaching, and explores how to strengthen schools enterprises cooperation under the environment of big data and to improve the quality of application oriented talents training.
\end{abstract}

\section{Introduction}

The "big data era" entering the $21^{\text {st }}$ Century has aroused the attention and concern of experts and scholars. "Big data" revolutionized the methods of data processing, provided a broad talent job positions for the state and society market and put forward new requirements and standards for the talents under the environment of big data. As the cradle to develop talents with high quality and high technology, colleges and universities have played an important role in the development of the science and technology of China. It is particularly critical to develop the application oriented talents in colleges and universities under large data environment ${ }^{[1]}$. With the deep development of the globalization of economy and science and technology, to reform the traditional schools enterprises cooperation teaching mode by using the advantage resources under the environment of big data can effectively improve the application oriented talent training quality. This paper analyzes the current situation of the traditional schools enterprises cooperation teaching, explores and researches the new ideas and new methods on how to strengthen the cooperation between colleges and enterprises and to improve the quality of application oriented talents training under the environment of big data.

\section{The Current Situation of the Traditional Schools Enterprises Cooperation Teaching}

Schools enterprises cooperation teaching of China began in 1980s. After more than 30 years of exploration and practice, there have been some breakthroughs, innovation and some success in the application oriented. Under big data environment, there are many difficulties and confusion on how to play the advantages of enterprises, colleges and universities. The cooperation mechanism is not perfect, the ideas are old and the main status is not clear and so on [3], which are restricting the quality of personnel training.

The Cooperation between Schools and Enterprises Does not have Enough Depth or Level. From the content to the form, the traditional school enterprise cooperation is relatively single and fragmented. Teaching units are separate. Cooperation resources (such as training base and part-time teachers) cannot be shared by colleges or enterprises, which causes a serious waste of resource. The cooperation objects of colleges and enterprises are often more than one, which has no relatively stability. The core interests of colleges and enterprises are different, which leads to the cooperation between the two sides has no continuity. The traditional school enterprise cooperation has greater form than the content with a lack of deep integration. Part of the school enterprise cooperation is limited to the level of personnel exchanges. Enterprises are not really involved in the process of school education, which forms the non nature and free developing state of schools and enterprises cooperation [5].

The Colleges and Universities are Positive while Enterprises Are not. The key of schools and enterprises cooperation is to achieve mutual beneficial and win-win situation. Colleges and universities should go deeply to enterprises to truly understand the requirements of enterprises for 
talent and ability, in order to cultivate marketable talents with high quality and skill to make the enterprise be satisfied. At the same time, schools are docking with enterprises and produce production practice. According to the actual production, colleges and universities play a solid professional theoretical knowledge and scientific research ability, and can carry out scientific and technological research work[6]. Therefore, it will be beneficial and initiative for colleges and universities to cooperate with enterprises.

As an economic entity taking benefit as the goal, enterprises accept students to enter the factory to practice, but the attitude is not very positive. Additional specialized technical personnel are required to organize, train and technically guide, which has affect to the normal production process and management of enterprises ${ }^{[7]}$. Security risks and production confidential leakage is inevitable and the enterprise has increased the cost and cost but also bear a greater risk. In addition, students are lack of practical ability and professional skills and knowledge, so they are difficult to meet the business requirements of the job. The university teachers are lack of engineering background and experience in the industry and their technical service capabilities are not uneven, so they are also difficult to service to the science and technology projects of enterprises. Under the conditions without the corresponding preferential policies of the state or the corresponding economic compensation of colleges and universities, enterprises have no enthusiasm to carry out schools and enterprises cooperation.

In the face of the future development of enterprises, how to realize the sustainable development under the environment of big data era? After all, it is the talent competition and talent is the core competitive power of the business development. The cooperation between schools and enterprises is an important guarantee for the cultivation of high-quality talents, which can provide excellent opportunity of high-quality talents needed in enterprise development, why enterprises are not interested in?

\section{Problems Faced by Enterprises}

Difficult to Hire Talents Which are Suitable for the Development of Enterprises. Higher education in China has experienced 30 years of rapid development and has conveyed a large number of talents for the country and society. Since $21^{\text {st }}$ Century, the education system still follows the mode under the planned economic system: schools carry out enrollment and teaching according to the plan. Although the education system has been reformed, the old one has a far-reaching impact on educators who still implement subject and record education with old-fashioned teaching methods and means. They do not have enough research on talent specifications, talent standard, knowledge structure and ability standards required in the society, which causes that talents training and social demands are separated from each other and enterprises are difficult to hire suitable talents for their own development needs. If they can temporarily find suitable talents, it has little role for enterprises to enhance the economic benefits.

The New Employees Training and Assessment are not Standard. Pre job training is teaching and training activities for new employee to have a certain understanding of the development of the corporate culture, job responsibilities and work system, to make them integrate into the team as soon as possible, to establish a positive working attitude and to make contribution to the enterprises. The enterprise does not have the standard training plan, training materials, even training teachers, only mobilizes department supervisors to act as the role of trainers, which makes the training become a mere formality. Both training and assessment are not standardized. The core value and culture of the enterprise cannot be properly transferred or inherited. The enthusiasm of new employees is not high and cannot reach the requirements of job positions. New employees will have no confidence in the job.

Low level of Technical Development is an Indisputable Fact. Since entering in $21^{\text {st }}$ Century, the old development ideas of enterprises that pay more attention on production than on development and more on current than on the future is of a significant power shortage. Only independent technology development can improve the core competitiveness of enterprises, which is one of the important ways to speed up technological progress. And many enterprises in our country only have 
"manufacturing" but no "creation", "property" but no "knowledge". There is no a research and development institution or researchers. Technology development cannot be carried out and there is no core technology. All the above will be the bottleneck restricting the development of enterprises.

The author believes that to enhance the core competitiveness of enterprises, we must carry out technical development, carry out independent innovation, strengthen cooperation with colleges and universities, build independent innovation platform of schools enterprises cooperation mode, enlarge and strength enterprises and get power for sustainable development.

\section{Thoughts and Methods of Strengthening Schools Enterprises Cooperation Teaching}

Give Play to the Guiding Role of the Government, Promote Schools Enterprises Cooperation. The schools enterprises cooperation is a good thing to benefit the country, which cannot only deliver high-quality talents for the country and the society, but also can inject the sustainable development to enterprises. It can be said that the guidance of government departments is an important catalyst for the development of schools enterprises cooperation. The government can take preferential policies for school enterprises cooperation, such as reducing a certain amount of tax of enterprises or take other means. The government should strengthen supervision to ensure the smooth development and implementation of schools enterprises cooperation to effectively improve the enthusiasm and initiative of the enterprises.

Jointly Participate in the Development of Personnel Training Programs and Carry out Teaching Practice Courses. To cultivate talents to meet the social development needs with high quality, universities and colleges should cooperate with enterprises and the Federation of Industry to jointly develop talent training scheme to make the scheme be more practicability and pertinence. The well-known entrepreneurs with rich experience in the aspect are invited to put forward constructive suggestions to specifications and objectives of talent cultivation and to jointly develop talent training scheme. Business line technical engineers are hired to carry out practice teaching where students directly learn new technologies and new processes, which greatly enhance the practicality and pertinence of the knowledge and teaching method.

Enterprises Develop Position Standards, Pre Job Training of Schools Enterprises Cooperation Come into the Classroom. The unified enterprise position standards developed by the Federation of Industry and cooperating enterprises should be brought into the basic content of college teaching to make students have a clear understanding to the standards, abilities, levels and requirements of the position before being employed, and to have targeted practice to graduate the professional requirements of the position as soon as graduate, improve the competition ability, and effectively raise the overall competitiveness of enterprises.

Jointly Develop the Mobile Digital Teaching Platform. Under the big data environment, open sharing is an important trend in the development of the global industry. The advantage resource sharing between schools and enterprises is an effective way to achieve a win-win situation. Mobile Internet technology has become an important tool for people to work and study. By integrating and sharing the advantage resources of universities, enterprises and industries, mobile Internet has become an effective way to promote the further development of schools enterprises cooperation. Integrate the resources of schools enterprises cooperation, organically combine the knowledge, skills and standards needed by enterprises, carefully organize the knowledge structure, assessment criteria, supervision mechanism, combine with the training process of colleges and universities, jointly develop mobile digital teaching platform, form the talent training mode with mutual participation of schools and enterprises, make teaching be more suitable for the society and development of the industry and get the win-win situation of enterprises and schools.

Build Schools Enterprises Collaboration Technology Research Platform and Establish a Long-term Mechanism for Independent Innovation. In the positive guidance of the government, both sides of schools and enterprises build collaborative research platform and set up research centers in colleges and universities. University teachers should play their important theoretical advantage, rely on the production practice of enterprises, get involved in the production guidance and technology research and development project, give independent innovation advice for 
enterprises, improve the innovation capacity of enterprises, establish a long-term mechanism of independent innovation of enterprises and to improve the core competitiveness.

\section{Conclusion}

The teaching of schools enterprises cooperation is an effective way to cultivate high-quality, practical and innovative talents. The traditional schools enterprises cooperation teaching modes which only had forms have already been unable to meet the needs of modern social science and technology progress, economic development and enterprise transformation. Entering the era of big data, enterprises must make timely adjustments to achieve sustainable development and to get out of the plight of development, which requires schools and enterprises jointly develop talent training programs and change the traditional teaching modes to effectively improve the quality of personnel training and to provide power for social development and scientific and technological progress.

\section{References}

[1] X. Fang. Discussion on the New Strategies of Application Oriented Talents Cultivation in Universities Under the Big Data [J].Education Exploration. 2015 (8): 48-49.

[2] S.H. Wu, H. Mou, M.P. Lin. Exploration on the Path of Schools Enterprises Cooperation under the Internet Environment [J]. Chinese University Science and Technology, 2016 (1): 116-118.

[3] W. Wu. Where should Schools Enterprises Cooperation Go in "Post demonstration" Era[J]. Human Resources.2014 (3): 29-33.

[4] Y.Q. Wang. Constraints and Solutions to the Deep cooperation between schools and Enterprises [J].Journal of Hubei Industry Career Technical College. 2012 (3): 16-19.

[5] Z.Y Zeng. How to Avoid the Dubious Marriage of Schools Enterprises Cooperations [N]. Chinese Education News. 2012(06).

[6] X.X. Liu, J.Y. Ma. On Schools Enterprises Cooperation in Higher Education Institutions[J]. Journal of the National Institute of Education Administration. 2005 (12): 76-78.

[7] X.X. Liu, X.L. Zhang. Analysis of Problems and Countermeasures of Schools Enterprises Cooperation in Vocational Colleges combing the Actual Work [J]. New Education Era Electronic Magazine (Teacher Edition). 2016 (2). 